\title{
Classroom Implementation Practices of the Secondary Level English Curriculum: A Case of Nepal
}

\author{
Manita Karki
}

\begin{abstract}
Curriculum is a whole educational programme to fulfil the objectives of national educational system that provides the fundamental frame for the teachers to teach in schools. The school level English language curriculum in Nepal aims at developing a comprehensive communicative competence in learners. This paper attempts to explore the extent to which English language teachers teaching at secondary level in Nepal understand the English curriculum and implement it in their classroom teaching. The paper is based on my graduate research project at Kathmandu University which involved eight English-language teachers from the Kathmandu valley for interview and observation to collect required information. The paper accomplishes the thesis that EFL teachers make sense of knowledge of curriculum at theoretical level; however it has not been utilized, as it should be, in their classroom practices.
\end{abstract}

Key words: Curriculum, teaching strategies, evaluation, implementation of curriculum

\section{Introduction}

Curriculum as an educational programme states the purposes and also the content, teaching procedures and the learning experiences necessary to achieve these purposes. Likewise, it also includes some means for assessing whether or not the educational ends have been achieved (Richards, et al., 2002). Language in school level curriculum in Nepal is seen as a skill that allows one to get things done. The things done through language are described as functions such as expressing likes and dislikes, good wishes, etc. Therefore, students are expected to internalize grammar rules naturally and use correct and grammatical language both in written and spoken expression (CDC, 2007). In Nepal,
Curriculum Development Centre (CDC) takes the lead to develop all the curricula. It makes the attempts to revise those curricula over time. The knowledge of curriculum is crucial for teachers because it provides them with overall framework to guide students towards the right direction. Furthermore, it provides a path to teachers and their teaching. However, the success depends on how this document as the core part of whole educational programme - is interpreted and used by the teachers.

Recounting my own experience, I have been facilitating English as a compulsory course in school levels for seven years. In initial days, I did not have any idea about the curriculum. I merely went through the prescribed textbooks. Later I heard about 
curriculum in a training event. Then I went through the secondary level curriculum of English. The knowledge of curriculum paved the easy way in my teaching. I realised that this makes teachers' job more systematic and provides frame for teaching. I started thinking about proper utilization of curricula in a wider English language teaching community in Nepal. I also observed that there were contexts where teachers simply depended on the textbooks for their lifetime. It encouraged me to examine the implementation of the curriculum in real ground among teachers.

The curriculum guides textbook designing processes, selection of contents, use of appropriate teaching learning methods, strategies, use of skills, and implementation of the textbooks in classroom teaching and helps to evaluate the overall learning process. For teachers, curriculum is a great resource for preparing lesson plans, selecting appropriate methodologies and materials. It also helps to organize lesson delivery, assessment system and keeps instruction organized. CDC improves the curriculum time and again revising it to meet the current needs. National Curriculum Framework (2007) has also placed high emphasis on the use of curriculum in teaching and learning processes at school level. The framework points out that the curriculum has been underused in school education system for years.

It is significant to explore EFL teacher's knowledge and practice of curriculum to improve the existing situation. There has been little effort on the exploration of what EFL teachers know about curriculum. Moreover, there are doubts on the implementation part of such knowledge in practical situations. Even though many EFL teachers have the theoretical knowledge of curriculum, they fail to utilize it in their teaching profession (Tanner\& Tanner,
1991). Moreover, teachers' understanding and implementation of curriculum is essential as they are the primary people to implement the curriculum at real ground. It is important to see this gap of knowledge at theoretical and practical levels with reference to develop policies and programs to upgrade the standard of teaching and learning activities.

\section{The study design}

The major question of the study was - how do the Nepalese secondary level EFL teachers' perceive and implement the English curriculum in their classroom teaching? To make the study more specific to get required information related to the problem, the following research sub-questions were designed a) How do ELT teachers make meaning of curriculum? b) What factors hinder or facilitate teachers to implement the curriculum in classroom teaching? c) What changes, do the teachers think, need to be introduced in the current curriculum?

The study followed the interpretive research paradigm. Interpretative paradigm is naturalistic and the researcher tries to understand phenomenon in terms of meanings people bring to them (Bryman, 2001). I appreciated and interpreted the reality of teachers' perspectives towards the curriculum and its implementation in lived experiences. Interview and observation were key techniques in my research. The research was designed on the basis of ethnographic framework that encourages careful description of ordinary conscious experience of everyday practice and the culture of that context for one and half months. The study involved eight English-language teachers working in secondary level for last 8 to 15 years, located in the Kathmandu Valley. I chose them purposively. They haduniversity degrees in teaching English. 


\section{Results}

While analyzing the data, due attention was given to the activities performed by the participants in the classroom and ideas expressed by them during the interview sessions. The data was studied and analyzed thematically using data triangulation approach. The data was further interpreted linking them with the already established theories available in ELT literature. The findings were categorized under different themes:

\section{Knowledge of 'curriculum'}

Curriculum is a design to control or to bind the content of a particular subject (Kelly, 2004). Most of the participants in the study (T1, T2, T5 and T8) also expressed their views in similar line, 'curriculum is a guide for teacher which helps to run the class effectively". In a broader sense one of my participants said "Curriculum is something more than just a set of plan. It is a guide for a teacher, which focuses on particular objective, certain language skills for development, and covers several aspects of teaching methodology and strategies". Curriculum attempts to fulfil the needs of contemporary society and the expectations of the nation from the particular level. It is "a plan made for conducting any educational program in systematic patterns to achieve the certain goal or targeted aims" (Pandey, 2008). Curriculum encompasses multiple elements as it embodies various aspects such as who to teach, what to teach, why to teach, how to teach and when to teach as well as where to teach. Therefore, curriculum includes objectives, contents, teaching-learning strategies and evaluation. From the study it was found that the teachers were aware of these basic elements of the curriculum.

\section{Views on objectives of the curriculum}

Objectives of the school level curriculum are framed grade-wise and level-wise. Three participants (T1, T4 and T5) out of eight stated that the main objective of secondary level English curriculum was to enhance the language skills and make the learners enhance communicative competence in English language whereas, two participants (T7 and T8) stated - "Making the learners able to know the diverse culture and context of the nation and apply it in real life communication". The remaining participants were found neutral in this regard. It indicates that communicative competence and societal aspects of ELT are the focus of the participants in relation to the objectives of the curriculum.

\section{Knowledge and views on content}

Content is another important element of curriculum. After the selection of objectives, selection and gradation of content that contain appropriate learning experiences is necessary. Majority of the participants expressed positive views toward present curriculum. One of the participants stated:

The present English curriculum of secondary level has incorporated national and international contexts to teach different language functions which are included in secondary education content. So, the contents are welldesigned and equal priority has been provided for all language skills. However the issues and topics are not updated for the last 10 years, which makes teaching and learning monotonous. So it would be better to change the topics and issues as per the interest of students and changing situations.

It shows that the teachers had knowledge of the curriculum in use and they were 
found critical towards the content coverage of the present curriculum.

\section{Teaching learning strategies}

Teaching-learning strategies are the methods, procedures, process, techniques and designed plans through which the selected subject matters are taught or disseminated to the learners. Since teaching-learning process uses a certain text in the classroom, there is a close relationship between subject matters and teaching methods (Richards \& Schmidt, 2002). One of the participants (T8) put his opinion about the teaching-learning strategies in this way:

English curriculum has mentioned teachers' activities, learners' activities' as well as teaching learning activities and process, it has also included communicative language teaching activities, learner centred teaching approaches, teacher as a facilitator, taskbased language teaching approach, etc as teaching learning strategies, which I frequently use during teaching..

As the participants shared their knowledge of the strategies, it can be inferred that they have sufficient understanding about the teaching strategies mentioned in curriculum.

\section{Evaluation}

Generally, the process used to appraise whether the learners achieve intended objectives or not is called evaluation (Richards \& Schmidt, 2002). The achievement of the learners can be measured by comparing intended objectives and real achievement of learners. Teachers need to be familiar with the evaluation process the curriculum has envisioned. When asked about the concept of evaluation, a participant teacher (T6) said:
Evaluation is the process of determining to what extent the educational objectives are actually being realized after teaching, it helps to know the level of competency of learners and provide necessary feedback to them. I frequently use formal and informal evaluation techniques like dictation, composition, note-taking and oral tests to evaluate overall performance of students.

This response shows that teachers have knowledge and understanding of the concept of evaluation.

\section{Use of curriculum in classroom teaching}

I tried to explore participants' ideas about the importance of having knowledge of curriculum for effective classroom teaching. I asked a few questions like these: Is it necessary to have knowledge of curriculum? Why is it necessary for a teacher to have knowledge of curriculum? Responding to my questions, participant T3 articulated:

I use curriculum because it helps me to prepare annual, general and unit plans which we all need to submit at the beginning of the year. Not only that it also gives the ideas to select and design the teaching learning approaches, principles and activities useful for a particular lesson.

Similarly, T1, T5, T6, T7 and T8 also expressed similar opinions. They all mentioned that they used the curriculum to design annual general plan which they need to submit to their Head of Department (HOD) in the beginning of the year. According to T5, the study of curriculum helps to run the classes effectively i. e. to make students comprehend the lesson and develop the teachers' ability to tackle the problem during teaching, such as the use of necessary methods and techniques and assessment of learning outcome, etc. Likewise T7 also used the 
curriculum to make annual plans and to check teaching and learning processes. T8 used curriculum to meet the objectives of teaching and to conduct various kinds of activities in the class according to the lesson suggested by the curriculum.

So when teachers design their annual plan, unit plan or daily lesson plan they can refer to those goals and design the activities as suggested by the curriculum which help them to achieve the intended goals.

\section{Linking teaching aims with the curriculum}

The knowledge of EFL curriculum helps the teachers change their teaching strategies according to the expected learning outcomes but it depends on how a particular teacher incorporates curriculum during his/her teaching hour (Russell, 2000). During the interview, I tried to explore about the inclusion of curriculum during teaching hours through in-depth interviews and classroom observation of the teachers. T1, T4 and T5 mentioned that one of the objectives of secondary level curriculum is to enhance communication and language skills. For that they use different teaching learning strategies as per the need. Two participants (T7 and T8) expressed that making the learners able to know the diverse culture and context of the nation and apply it in real life communication is the goal of the curriculum. But the classroom teaching observation shows different reality.

\section{Observation 1}

The Teacher distributed some newspapers and asked students to read the news and compare it with the news on page 155 in their book. Then the students did it individually and noted down the similarities and differences of news patterns. The teacher asked the students to tell the answer and wrote down on the board. Then she described the patterns of writing herself, and asked students to develop a news story in a similar pattern. A few selected students shared their write up in class. The teacher observed without any comments.

After the class observation, I asked the teacher "What was your focus in today's' lesson? How did it fulfil the objective? And which objective was fulfilled from today's class?" The teacher viewed in this way -

"I was just thinking about whether the students can read text extensively and intensively or not and whether they are able to scan the information given there or not. My plan was to make students write something about any news and I thought that students would be able to do that. It helps to develop their language proficiency and communication skill and I gave them time to express their views through writing and they have done and that focus on writing skill as well like this the curriculum objectives is fulfilled and use to fulfil."

The aim of communicative language teaching is acquisition of communicative competence via student engagement in meaningful use of language at discourse level (Richards \& Rodgers, 2001). To achieve this, the teacher facilitates communicative activities by managing the classroom environment, providing resources and acting as a communicator. 'Classroom activities are often designed to focus on completing tasks that are mediated through language or involve negotiation of information and information sharing' (ibid, p. 165). But, in my observation, there were rare cases of enhancing any communicative, interaction-based discussion between the teacher and students. Neither did they take account of the contexts. 
The entire teaching and learning remains textbook-based, test-oriented and completely teacher-centred. But this was not the case with each and every teacher. I found some noticeable differences between some teachers and their teaching pattern. For example;

\section{Observation 2}

The teacher asked a few questions - how many of you have read extra books? Which is your favourite book and why? A few students raised their hands and replied the answers. The teacher divided students into the groups of five and asked them to read two passages from the text. He asked them to discuss and make five wh-questions answers of which they knew. Then the students asked their questions to other group members one by one and discussed whether their answers were right or wrong. The teacher acted as a facilitator and at the end explained the passages.

This way, the whole class got a chance to interact with each other and enhance the communicative skills. This is the reason behind vast differences among the same level of students' understanding and skills, though they were studying the same textbook. Content is not whole, it needs to be presented systematically for proper linkage between teaching and curriculum objectives. For this the teacher needs to be aware of the expected aims and objectives of the text and curriculum.

\section{Prospects for further improvement in curriculum}

Curriculum need to be improved on a continuous basis to meet the demand of the time. When asked about the suggestions for changes in the curriculum, T2 expressed:

The present curriculum should include some grammar functions. In SLC grid twelve types of grammar items are included but all the grammar functions have not been covered by the curriculum clearly and nor has it dealt with them separately. All are mixed and create confusion for the teacher as for example, writing news report, news story, news article are mixed up. It has not been mentioned clearly in curriculum that these three things need to be taught differently.

The teacher further added that - "There are some topics suggested by the curriculum which are out of date and are not the interest of students. CDC can include topics which are based on the current situation." The teacher also pointed towards a need to include literature in the course when she mentioned - "Next thing is that curriculum lacks literature part, it should include topics like poem, drama, stories etc which will increase the interest of students."

I also noticed that the curriculum failed to differentiate clearly about writing news report, news story and news article. It has just included these three things without clear explanation about how to teach these things. The teacher (T2) also suggested that the curriculum needs to be updated on a regular basis. Similar ideas were expressed by CDC 2007 in National curriculum framework for school education in Nepal mentioning that "the present curriculum is not a complete package of all the elements that we need to include and it lacks something which we need to revise and include time and again to make it perfect" (p. 21).

Similar opinions were expressed by T1, T5 and T6. According to them, the present curriculum is not revised for a long period of time so the content is not as per the interest of students and up to their level. According to T1 different types of topics need to be included like topics related to science and technology, present issues of our society and context, global issues etc. Moreover, there should be clear instructions for teachers 
about how to relate the local cultural context with global issues and proper training for better use of curriculum in classroom teaching. These views were quite similar to the view of CDC (2007) which states "curriculum will gradually be implemented by making it inclusive. In doing so, need based curriculum will be developed by giving special attention to special needs children, making school calendar flexible, teaching as per the interest of children, localizing the curriculum" (p. 34). While observing these participants' classes, I found that they were fully dependent on textbook which was designed following the prescribed curriculum. So it is necessary for CDC to design and revise the curriculum on a timely basis with proper research. So the management of a curriculum must therefore try to ensure that there is continual but gradual change (Sharma, 1999).

On the other hand, T3 expressed a different version arguing that writing needs to be focused more than other skills. He mentioned:

I think writing needs to be focused more because everyone can comprehend the text, read the text and solve the exercises but when it comes to writing something, it really creates problem... In curriculum there are just two or three activities suggested to evaluate the writing comprehension: question-answer, writing essay, and developing a paragraph which is not sufficient.

When we go through the curriculum we can see that the allocation of marks for each skill has been divided differently. For example, listening, speaking, reading and writing have been given $10 \%, 15 \%, 45 \%$ and $30 \%$ of the total weight. If we go through the curriculum and prescribed textbook, we can see that there is a dearth of activities to enhance writing skills in comparison to reading activities.

\section{Discussion}

This discusses the results of the study related to teachers' knowledge of curriculum, teaching aims and curriculum, factors affecting the curriculum implementation and future prospects of curriculum development.

\section{Knowledge of curriculum}

The study indicated that EFL teachers have general knowledge of curriculum at theoretical level. Further, it displayed the fact that Nepali EFL teachers make sense of curriculum in terms of communicative competence and societal aspects of ELT. There is a common agreement among participants of the study on the selection and gradation of contents. It shows that contents are well designed and equal priority has been given to all language skills. However, several issues and topics are not updated for the last 10 years, which made the teaching and learning monotonous. Teachers bear sufficient knowledge of teaching strategies and activities in relation to CLT. It is important to mention that many EFL teachers can understand and explain CLT in our context. They make sense of it in terms of guiding principles, characteristics, strategies, role of teachers and students, its advantages and criticism. But there are always doubts at the implementation level. Likewise, teachers seemed to be well familiar with evaluation process, feedback and several tools at this level. For instance, they are capable of using 
formal and informal evaluation techniques like dictation, composition, note-taking and oral tests to evaluate overall performance of students in English.

\section{Curriculum and teaching aims}

The study clearly articulated the fact that teachers do not use the curriculum while designing their annual plan, unit plans or daily lesson plans. Instead, they solely depend on the textbook in these planning. It unfolded a few cases of enhancing any communicative, interaction-based discussion in between teacher and students. Teachers hardly take account of contextualization of teaching items, skills or aspects. The entire teaching and learning remains textbook-based, test-oriented and completely teacher-centred although there are a few teachers who have been able to utilize the curriculum in their day-to-day teaching.

\section{Factors affecting curriculum implementation}

The study confirms that the level of the students, school environment, and common concept about curriculum are influential factors in the implementation of the curriculum besides personal factors of the teachers such as availability of time. Allocating time for teachers to plan curriculum implementation and providing technical support are necessary for promoting curriculum implementation in the Nepali context. Environmental and extrinsic factors are critical elements for the effective curriculum implementation (Russell, 2000). Nepalese teachers mainly face problems because of the time constraint and inadequate resources and the lack of space and facilities. It was found that most of the problems are interrelated. Likewise, the lack of resources and children with limited exposure in English have equal effect on the degree of the curriculum being implemented.
In such cases, it is obvious that teachers have to grapple with the children's lack of language ability as well as the problems related to the lack of resources. On the other hand, intrinsic factors such as knowledge of professional area, interest in teaching and motivation are significant features in the delivery of the program and can be barriers for the proper curriculum implementation (Erden, 2010). To tackle these problems, school administration, $\mathrm{CDC}$ and training centres need to run the training and workshops and provide the knowledge of proper use of curriculum in teaching learning process along with regular follow-ups.

\section{Future prospects for curriculum development}

Among various measures to help improve the current status, the experienced teachers can be used to train the new and inexperienced teachers. Though CDC has attempted to revise the secondary level English curriculum, it is not timely. It needs to address the content-based issues in relation to local culture and culture. The present study showed that there has been little use of curriculum in classroom teaching in private English medium schools. It also specifies that there is a need of making teachers involved in developing the curriculum so that they could make good sense of state education and bring meaning to classroom teaching. Necessary changes in curriculum and at its implementation level are inevitable for better English language education. The curriculum change can be described as the transformation of the curriculum scheme such as goals and objectives, content, design or it could be done in more minor sense by modifying the curriculum such as changing the learning activities and adding one more topic to the curriculum. In fact, as to educate society towards the changes in the world, curriculum change is inevitable 
(Bondi \& Wiles, 1998). Besides, the teacher training programs should inform the future teachers about the use of curriculum in classroom teaching.

\section{Conclusion}

The study indicated that Nepalese EFL teachers have sound knowledge of curriculum but very few of them utilize it during teaching. Teaching environment and some intrinsic factors like lack of motivation hinder them from using it in real teaching and learning. Similarly, the study also enunciated the fact that teachers rarely use the curriculum in their planning. Many of them solely depend on the textbook in this regard. No training and workshop have been organized for teachers to help them learn how to make use of the curriculum in classroom teaching. Curriculum is not just a set of plans or guidelines for designing a textbook; it is a complete package for those who are directly or indirectly involved in education. It also prescribes the methodology that the teachers need to apply while teaching. Contrary to this notion, the present study revealed that the EFL teachers have reasonable knowledge of elements of curriculum at the theoretical level but they rarely utilize it in EFL teaching and learning process practically. Ignoring the essence of curriculum this way will lead the EFL teachers nowhere. Therefore, it is necessary for all the stakeholders to understand the importance of curriculum in guiding the teaching-learning activities and use it appropriately to achieve the desired outcome.

\section{About the author}

Manita Karki is an English language teacher in Nepal. Currently, she is pursuing her $M$
Phil in English language education from Kathmandu University. Her major area of interest includes language policy and planning. She is a life member of NELTA.

\section{References}

Bondi, J., \& Wiles, J. (1998). Curriculum development: A guide to practice. New Jersey: Merrill

Bryman, A. (2001). Social research methods. Oxford; Oxford University Press.

Curriculum Development Centre (2000). Secondary English curriculum. Bhaktapur, Nepal: Author.

Curriculum Development Centre (2007). National curriculum framework for school education in Nepal. Bhaktapur, Nepal: Author.

Erden, E., (2010). Problems that pre-school teachers face in the curriculum implementation. An unpublished dissertation, Middle East Technical University.

Kelly, A.V. (2004). The curriculum theory and practice. London: Sage Publication.

Pandey, C. S. (2008). Curriculum and evaluation. Kathmandu: Kshitiz Prakashan.

Richards C. J. \& Rodgers T. S. (2001). Approaches and methods in language teaching. Cambridge: Cambridge University Press.

Richards J.C. \& Schmidt, R. (2002). Longman dictionary of language teaching and applied linguistics. Pearson Education Limited.

Russell, J. (2000). The role of curriculum in teacher development. Cambridge: Massachusetts Avenue. 
Sharma, S. R. (1999). Issues in curriculum administration. New Delhi: Pearl Publishing House.

Tanner, D., \& Tanner, N. L. (1981). Curriculum development: theory into practice. Columbus, Ohio: Prentice Hall.

\section{Appendix}

\section{Observation Outline}

Date:-

Class:-

Unit:-

Topic:-

Teacher's Name:-

Language Functions and skills:

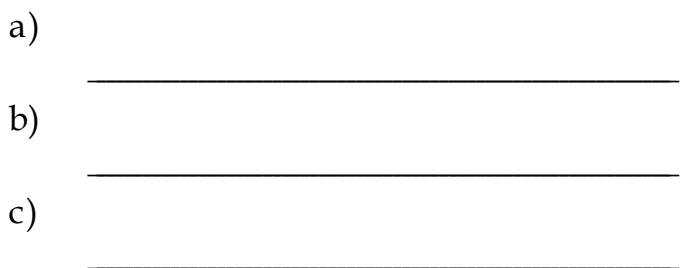

Language functions and skills taught:

a)

b)

c)

Objectives in the curriculum:

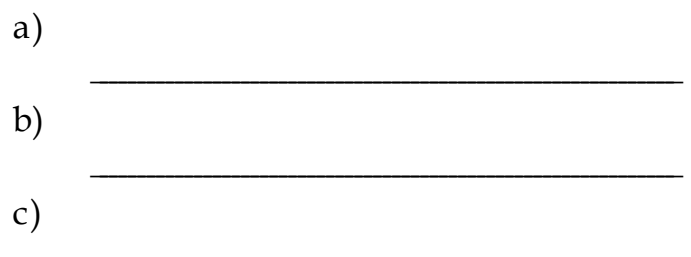

a)

b)

c)

Use of materials:

a)

b)

c)

Methods and techniques suggested by the curriculum

a)

b)

c)

d)

Used of teaching methods, techniques and procedures:

a)

b)

c)

d)

Activities and procedure:

Objectives set by the teacher: 
3. How do you define the word "curriculum"?

4. Can you say a few objectives that pointed out in curriculum?

Evaluation process:

5. How do you incorporate the objectives set by the curriculum in your classroom teaching?

Comments (if any):

6. Do you concentrate on meeting the objectives while teaching? How do you do so?

Suggestions (if any):

\section{Post-interview}

7. What is your focus in today's' lesson? What is its link to the curricula

Observed by: objectives?

\section{Interview - 1}

8. Which objective was fulfilled by today's your class? How? Were all the objectives met?

\section{Questions;}

\section{Pre-interview}

1. Do you have curriculum of English with you?

2. Did you go through the curriculum? Why?

9. What are the factors that hinder or facilitate you to implement the curriculum in the classroom teaching?

10. Is there something that you would like to have changed in this curriculum? What? Why? 